\title{
Stability Analysis of an Inverted Pendulum on a Cart with the Presence of Restoring and Frictional Forces Disturbance using Observer Based and Full State Feedback H2 Controllers
}

\author{
Mustefa Jibril ${ }^{1}$, Messay Tadese ${ }^{2}$, Fiseha Bogale ${ }^{3}$ \\ ${ }^{1}$ Msc, School of Electrical \& Computer Engineering, Dire Dawa Institute of Technology, Dire Dawa, \\ Ethiopia \\ ${ }^{2}$ Msc, School of Electrical \& Computer Engineering, Dire Dawa Institute of Technology, Dire Dawa, \\ Ethiopia \\ ${ }^{3}$ Msc, Department of Mechanical Engineering, Kombolcha Institute of Technology, Wollo, Ethiopia \\ mustefa.jibril@ddu.edu.et
}

\begin{abstract}
In this paper, the stability control of the inverted pendulum on a cart with a disturbance forces has been done using observer based and full state feedback $\mathrm{H} 2$ controllers. The Lagrangian equation has been used to model the system equation of motions and linearized the system to the unstable upward position. Comparison of the system stability has been simulated by comparing the proposed controllers using Matlab/Scripts and a promising results has been analyzed successfully.

Keywords: Inverted pendulum on a cart, Observer based controller, Full state feedback H2 controllers

\section{Introduction}

An inverted pendulum on a cart is a pendulum system that has its center of mass above its pivot point. It is nonlinear and unstable without an additional feedback control system. The inverted pendulum stability is a major problem in dynamics and control strategy and is used as a controller testing mechanism. Most of the applications used in this system is a 1 degree of freedom by arranging the pole to a fixed axis of rotation. In order to improve the stability of an inverted pendulum in its inverted position, a feedback control theory based controller can be used, which regulates the angle of the pendulum and moving the pendulum mass when the system starts to fall over, to keep it in upraise zero-degree angle from the vertical position. One of the inverted pendulum application is rocket or missile guidance.
\end{abstract}

\section{System Discription}

The inverted pendulum on a cart system model is shown in Figure 1 below. 


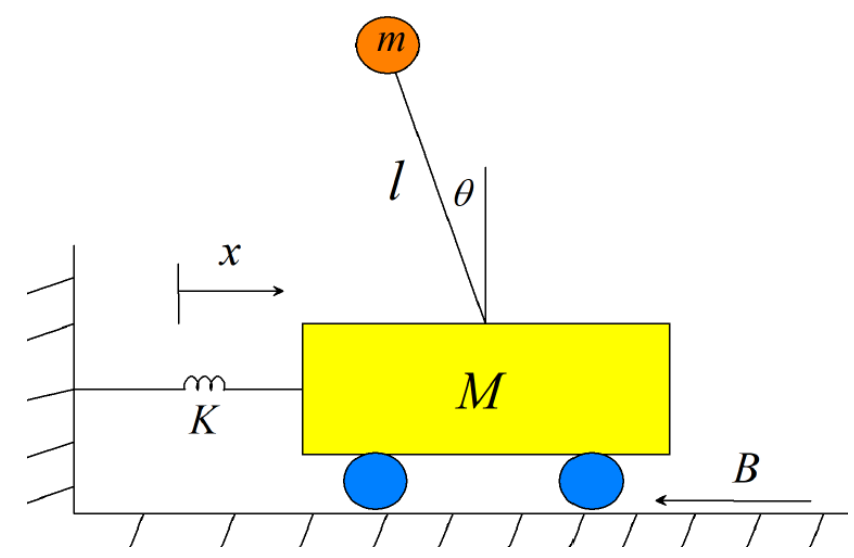

Figure 1 Inverted pendulum on a cart system model

The equations of the system motion tins be derived easily using Lagrange's equations. Referring to the diagram model where $\mathrm{x}(\mathrm{t})$ is the position of the cart, $\theta(t)$ is the angular position of the pendulum with respect to the regular upraise position and the opposing forces of the spring and friction and an external force in the $\mathrm{x}$-direction, the Lagrangian $\mathrm{L}=\mathrm{T}-\mathrm{V}$, where $\mathrm{T}$ is the kinetic energy for the system and $\mathrm{V}$ the potential energy, so the written out equation for $\mathrm{L}$ is:

$$
L=\frac{1}{2} M v_{1}^{2}+\frac{1}{2} m v_{2}^{2}-m g l \cos \theta
$$

where $\mathrm{v} 1$ is the velocity of the wagon and $\mathrm{v} 2$ is the velocity of the mass $\mathrm{m}$. $\mathrm{v} 1$ and $\mathrm{v} 2$ can be expressed in terms of $\mathrm{x}$ and $\theta$ by manuscript the velocity as the first derivative of the position;

$$
\begin{aligned}
& v_{1}^{2}=\dot{x}^{2} \\
& v_{2}^{2}=\left(\frac{d}{d t}(l \cos \theta)\right)^{2}+\left(\frac{d}{d t}(x-l \sin \theta)\right)^{2}
\end{aligned}
$$

Simplifying the expression in Equation (3):

$$
v_{2}^{2}=\dot{x}^{2}-2 \dot{x} l \dot{\theta} \cos \theta+l^{2} \dot{\theta}^{2}
$$

The Lagrangian is now given by:

$$
L=\frac{1}{2}(M+m) \dot{x}^{2}-m l \dot{x} \dot{\theta} \cos \theta+\frac{1}{2} m l^{2} \dot{\theta}^{2}
$$

The resultant force applied on the cart are

$$
F-B \dot{x}+K x=0
$$

and the equations of motion are: 


$$
\begin{aligned}
& \frac{d}{d t}\left(\frac{\partial L}{\partial \dot{x}}-\frac{\partial L}{\partial x}\right)=F-B \dot{x}-K x \\
& \frac{d}{d t}\left(\frac{\partial L}{\partial \dot{\theta}}-\frac{\partial L}{\partial \theta}\right)=0
\end{aligned}
$$

substituting $\mathrm{L}$ in these equations and simplifying leads to the equations that describe the motion of the inverted pendulum:

$$
\begin{gathered}
(M+m) \ddot{x}+B \dot{x}+K x-m l \ddot{\theta} \cos \theta+m l \dot{\theta}^{2} \sin \theta=F \\
m l(-g \sin \theta-\ddot{x} \cos \theta+l \ddot{\theta})=0
\end{gathered}
$$

These equations are nonlinear, but since the goal of a control system would be to keep the pendulum upright the equations can be linearized around $\theta \approx 0$.

Then after linearization, Equation (9) and Equation (10) becomes

$$
\begin{gathered}
(M+m) \ddot{x}+B \dot{x}+K x-m l \ddot{\theta}=F \\
m l(-g \theta-\ddot{x}+l \ddot{\theta})=0
\end{gathered}
$$

Rearranging Equation (11) and Equation (12) yields to the two equations

$$
\begin{gathered}
M \ddot{x}+B \dot{x}+K x-m g \theta=F \\
m l \ddot{\theta}-(M+m) g \theta+B \dot{x}+K x=F
\end{gathered}
$$

Let

$$
x_{1}=x, x_{2}=\dot{x}, x_{3}=\theta, x_{4}=\dot{\theta} \text { and } u=F
$$

Then the state space equation becomes

$$
\begin{aligned}
& {\left[\begin{array}{l}
\dot{x}_{1} \\
\dot{x}_{2} \\
\dot{x}_{3} \\
\dot{x}_{4}
\end{array}\right]=\left(\begin{array}{cccc}
0 & 1 & 0 & 0 \\
\frac{-K}{M} & \frac{-B}{M} & \frac{m g}{M} & 0 \\
0 & 0 & 0 & 1 \\
\frac{-K}{m l} & \frac{-B}{m l} & \frac{(M+m) g}{m l} & 0
\end{array}\right)\left[\begin{array}{l}
x_{1} \\
x_{2} \\
x_{3} \\
x_{4}
\end{array}\right]+\left[\begin{array}{c}
0 \\
\frac{1}{M} \\
0 \\
\frac{1}{m l}
\end{array}\right] u} \\
& y=\left(\begin{array}{llll}
0 & 0 & 1 & 0
\end{array}\right)\left[\begin{array}{l}
x_{1} \\
x_{2} \\
x_{3} \\
x_{4}
\end{array}\right]
\end{aligned}
$$


The parameters of the system are shown in Table 1 below

Table 1 System parameters

\begin{tabular}{|l|l|l|l|}
\hline No & Parameter & Symbol & Value \\
\hline 1 & Cart mass & $\mathrm{M}$ & $6 \mathrm{Kg}$ \\
\hline 2 & Pendulum mass & $\mathrm{m}$ & $1.5 \mathrm{Kg}$ \\
\hline 3 & Rod length & $l$ & $0.6 \mathrm{~m}$ \\
\hline 4 & Spring stiffness & $\mathrm{K}$ & $0.75 \mathrm{~N} / \mathrm{m}$ \\
\hline 5 & Friction coefficient & $\mathrm{B}$ & $1.2 \mathrm{~N}-\mathrm{s} / \mathrm{m}$ \\
\hline 6 & Gravity acceleration & $\mathrm{g}$ & $9.8 \mathrm{~m} / \mathrm{s}^{\wedge} 2$ \\
\hline
\end{tabular}

The state space representation numerically becomes

$$
\begin{aligned}
& {\left[\begin{array}{l}
\dot{x}_{1} \\
\dot{x}_{2} \\
\dot{x}_{3} \\
\dot{x}_{4}
\end{array}\right]=\left(\begin{array}{cccc}
0 & 1 & 0 & 0 \\
-0.125 & -0.2 & 2.45 & 0 \\
0 & 0 & 0 & 1 \\
-0.83 & -1.3 & 81.7 & 0
\end{array}\right)\left[\begin{array}{l}
x_{1} \\
x_{2} \\
x_{3} \\
x_{4}
\end{array}\right]+\left[\begin{array}{l}
0 \\
0.17 \\
0 \\
1.1
\end{array}\right] u} \\
& y=\left(\begin{array}{llll}
0 & 0 & 1 & 0
\end{array}\right)\left[\begin{array}{l}
x_{1} \\
x_{2} \\
x_{3} \\
x_{4}
\end{array}\right]
\end{aligned}
$$

\section{The Proposed Controllers Design}

\subsection{Observer-Based Controller Design}

The deal with the general claim where only a subset of the states, or linear combinations of them, are obtained from measurements and are available to our controller. Such a guide lines is referred to as the output feedback problem.

The output of the system is

$$
y=C x+D u
$$

The block diagram of the inverted pendulum on a cart with the observer-based controller is shown in Figure 2 bellow.

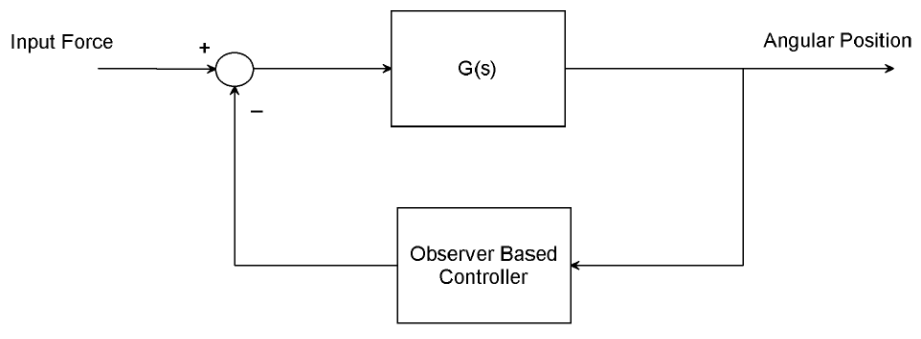


Figure 2 Block diagram of the inverted pendulum on a cart with the observer-based controller The observer based controller $\mathrm{Gc}(\mathrm{s})$ is derived as:

$$
G_{c}(s)=I-K(s I-A+B K+H C)^{-1} B
$$

With its state space realization

$$
G_{c}(s)=\left[\begin{array}{cc}
A-B K-H C & B \\
-K & I
\end{array}\right]
$$

The controller Gc(s) in Equation (17) is called the observer-based controller.

Where the state space configuration of the plant, $\mathrm{G}$, the state response gains vector $\mathrm{K}$, and the observer gain vector $\mathrm{H}$ are then returned, respectively.

The weighting matrix $\mathrm{Q}$ and $\mathrm{R}$ selected as

$$
Q=\left(\begin{array}{cccc}
1.3 & 0 & 0 & 0 \\
0 & 1.3 & 0 & 0 \\
0 & 0 & 1.3 & 0 \\
0 & 0 & 0 & 1.3
\end{array}\right) \text { and } R=2.4
$$

The observer gain vector selected as

$$
H=\left(\begin{array}{l}
1.5 \\
0.4 \\
0.7 \\
0.9
\end{array}\right)
$$

The state feedback gain vector $\mathrm{K}$ becomes

$$
K=\left[\begin{array}{llll}
-1.5304 & -2.6671 & 151.7035 & 16.8265
\end{array}\right]
$$

The observer-based controller state space representation become

$$
\begin{aligned}
\dot{x}_{o} & =\left(\begin{array}{cccc}
0 & 1 & -1.5 & 0 \\
0.1352 & 0.2534 & -23.74 & -2.86 \\
0 & 0 & -0.7 & 1 \\
0.8534 & 1.634 & -86.07 & -18.51
\end{array}\right) x+\left(\begin{array}{l}
1.5 \\
0.4 \\
0.7 \\
0.9
\end{array}\right) u_{o} \\
y_{o} & =\left(\begin{array}{llll}
-1.53 & -2.667 & 151.7 & 16.83
\end{array}\right) x_{o}
\end{aligned}
$$

\subsection{Full State Feedback $H_{2}$ Controller Design}

Consider Figure 3 and assume that 


$$
M=\left[\begin{array}{lll}
A & B_{1} & B_{2} \\
C_{1} & 0 & D_{12} \\
I & 0 & 0
\end{array}\right]
$$

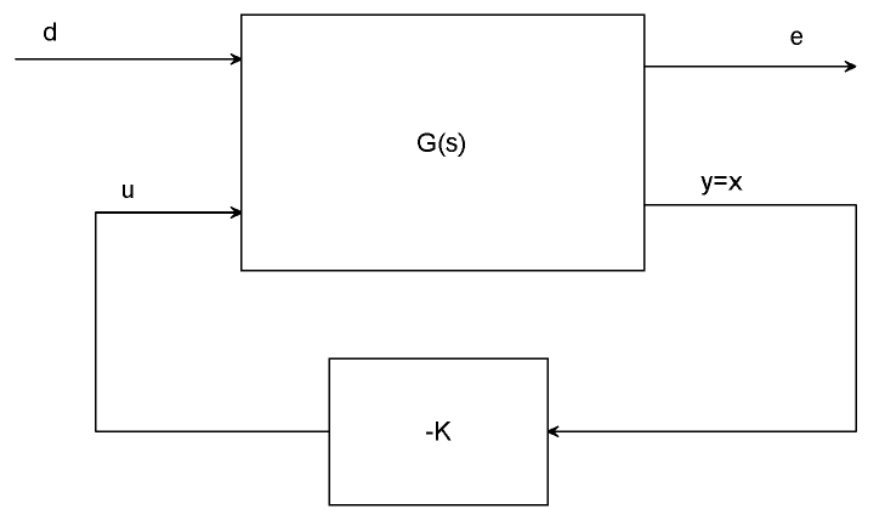

Figure 3 A full state feedback system.

From Equation (18),

$$
\begin{gathered}
\dot{x}=A x+B_{1} d(t)+B_{2} u(t) \\
e(t)=C_{1} x(t)+D_{12} u(t) \\
y(t)=x(t)
\end{gathered}
$$

Assuming that $\mathrm{d}(\mathrm{t})$ is the white noise vector with bunch intensity

$$
\left\|T_{e d}(s)\right\|_{H_{2}}^{2}=E\left(e^{T}(t) e(t)\right)
$$

Where

$$
e^{T} e=x^{T} C_{1}^{T} C_{1} x+2 x^{T} C_{1}^{T} D_{12} u+u^{T} D_{12}^{T} D_{12} u
$$

With Equation (19) and Equation (22), the minimization of $\left\|T_{e d}(s)\right\|_{H_{2}}$ is equivalent to the solution of the stochastic regulator problem. Setting

$$
Q_{f}=C_{1}^{T} C_{1}, \quad N_{f}=C_{1}^{T} D_{12} \text { and } R_{f}=D_{12}^{T} D_{12}
$$

the optimal state feedback law is given by

$$
u=-K x
$$

Where

$$
K=R_{f}^{-1}\left(P B_{2}+N_{f}\right)^{T}
$$

And 


$$
P\left(A-B_{2} R_{f}^{-1} N_{f}^{T}\right)+\left(A-B_{2} R_{f}^{-1} N_{f}^{T}\right)^{T} P-P B_{2} R_{f}^{-1} B_{a}^{T} P+Q_{f}-N_{f} R_{f}^{-1} N_{f}^{T}=0
$$

The system block diagram with full state feedback H2 controller is shown in Figure 4 below.

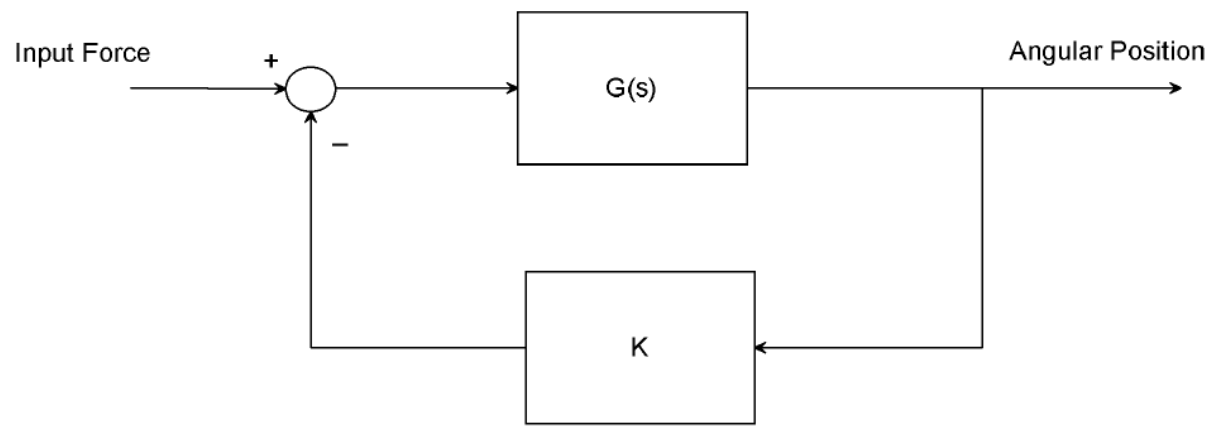

Figure 4 System with full state feedback $\mathrm{H} 2$ controller

It should be noted that the addition $\mathrm{K}$ is independent of the form B1. For this schemes the full feedback response gain matrix becomes

$$
K=\left(\begin{array}{llll}
0.8594 & 13.2809 & 76.9823 & 28.4267
\end{array}\right)
$$

\section{Result and Discussion}

\subsection{Comparison of the Inverted Pendulum on a Cart with Observer Based and Full State Feedback H 2 Controllers for an Impulse Input Force Signal}

The comparison response simulation of the inverted pendulum on a cart with observer based and full state feedback $\mathrm{H} 2$ controllers for an impulse input of $1 \mathrm{~N}$ force signal is shown in Figure 5 below.

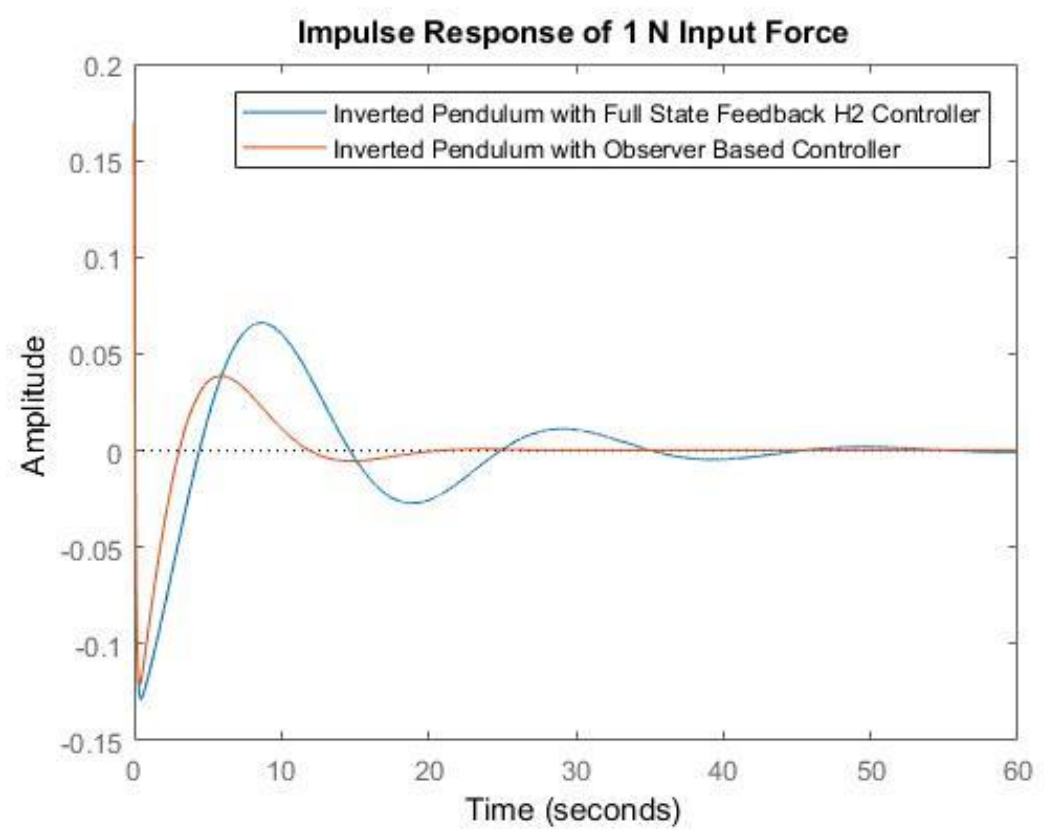

Figure 5 Impulse response 
The simulation result shows that the inverted pendulum on a cart with observer based controller has a high oscillation and overshoot with a long settling time as compared to the inverted pendulum on a cart with full state feedback $\mathrm{H} 2$ controller. The impulse response of the system with restoring and frictional forces does not affect the stability of the system but it makes the system to oscillate for a short time with 0.04 to -0.13 degree to a final zero-degree position of the pendulum.

\subsection{Comparison of the Inverted Pendulum on a Cart with Observer Based and Full State Feedback H 2 Controllers for a Step Input Force Signal}

The comparison response simulation of the inverted pendulum on a cart with observer based and full state feedback $\mathrm{H} 2$ controllers for a step input of $1 \mathrm{~N}$ force signal is shown in Figure 6 below.

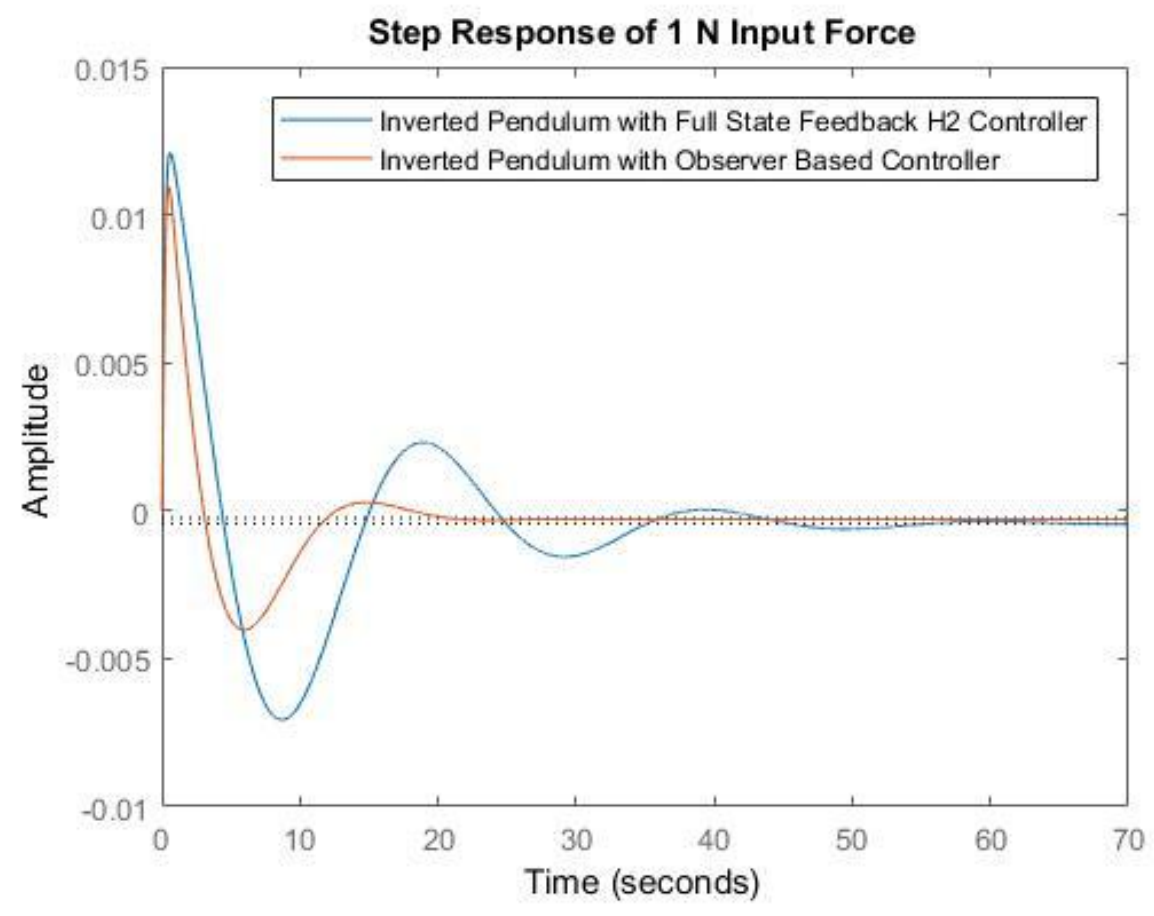

Figure 6 Step response

The simulation result shows that the inverted pendulum on a cart with full state feedback controller has a small oscillation and overshoot with a small settling time as compared to the inverted pendulum on a cart with observer based controller. The step response of the system with restoring and frictional forces disturbance does not affect the stability of the system but it makes the system to oscillate for a short time with 0.012 to -0.004 degree to a final zero-degree position of the pendulum.

\section{Conclusion}

In this paper, the comparison of the inverted pendulum on a cart stability has been done using observer based and full state feedback $\mathrm{H} 2$ controllers. Comparison of the system stability has been simulated by comparing the proposed controllers using Matlab/Scripts for an impulse and step input force signals. The comparison result of the impulse response shows that the inverted 
pendulum on a cart with observer based controller has a high oscillation and overshoot with a long settling time as compared to the inverted pendulum on a cart with full state feedback $\mathrm{H} 2$ controller while the comparison result of the step response shows that the inverted pendulum on a cart with full state feedback controller has a small oscillation and overshoot with a small settling time as compared to the inverted pendulum on a cart with observer based controller.

\section{Reference}

[1].M. J. Taha et al. "Robust Control Theory Based Performance Investigation of an Inverted Pendulum System using Simulink "Report and Opinion Journal, Vol. 12, Issue 6, pp. 1-6, 2020.

[2]. Mustefa J. T. et al. "Design and Simulation of a Steam Turbine Generator using Observer Based and LQR Controllers" Researcher Journal, Vol. 12, Issue 6, pp. 17-21, 2020.

[3].M. Jibril. T. et al. "Metal Cutting Tool Position Control using Static Output Feedback and Full State Feedback H2 Controllers" Report and Opinion Journal, Vol. 12, Issue 9, pp. 27 32, 2020.

[4]. Omer Saleem et al. "Robust Stabilization of Rotary Inverted Pendulum using Intelligently Optimised Nonlinear Self Adaptive Dual Fractional Order PD Controllers" International Journal of Systems Science, Vol. 50, Issue 7, pp. 1399-1414, 2019.

[5]. Morasso P. et al. "Quiet Standing: The Single Inverted Pendulum Model is Not So Bad After All” PLOS ONE, Vol. 14, Issue 3, 2019.

[6].Xiaoping H. et al. "Optimization of Triple Inverted Pendulum Control Process Based on Motion Vision” EURASIP Journal on Image and Video Processing, No. 73, 2018.

[7]. Saqib I et al. "Advanced Sliding Mode Control Techniques for Inverted Pendulum: Modelling and Simulation" Engineering Science and Technology, an International Journal, Vol. 21, Issue 4, pp. 753-759, 2018. 